\title{
Inhibition of prostaglandin synthetase in human rectal mucosa
}

\author{
C J HAWKEY* AND S C TRUELOVE \\ From the Nuffield Department of Clinical Medicine. John Radcliffe Hospital, Oxford
}

SUMMARY Miniaturised methods have been used to construct dose-reponse curves for the effects of inhibitory drugs on prostaglandin synthesis using individual rectal biopsies obtained from patients with ulcerative colitis. The potency of different drugs has been compared. Sulphasalazine, 5 amino salicylic acid (5-ASA) and $\mathrm{N}$-acetyl 5-ASA inhibited prostaglandin synthesis at high concentration, but sulphapyridine and prednisolone did not. Indomethacin and flurbiprofen were considerably more potent inhibitors. These data imply that sulphasalazine does not act by simple inhibition of prostaglandin synthesis but leave open the possibility that sulphsalazine or 5-ASA may be inhibitors of the synthesis of related lipoxygenase products.

Although sulphasalazine is widely used in the management of ulcerative colitis its mode of action remains unclear. Increased prostaglandin synthesis occurs during active ulcerative colitis. ${ }^{1-5}$ and it has been suggested that sulphasalazine or one of its cleavage products -5 amino salicylic acid (5-ASA) or sulphapyridine - may exert anti-inflammatory activity by inhibiting prostaglandin synthesis. ${ }^{2}$

In organ culture. 5-ASA inhibited synthesis of $\mathrm{PGE}_{2}$ to a greater extent than sulphasalazine and sulphapyridine..$^{2}$ but this result could have arisen through a non-specific effect on cell viability. In another report, a specific ability to inhibit the prostaglandin synthetase (cyclooxygenase) of human rectal mucosa was shown for sulphasalazine but its cleavage products were not investigated. ${ }^{3}$

In the present study we compared the potency of sulphasalazine and its cleavage products with indomethacin and flurbiprofen as inhibitors of prostaglandin synthetase using individual rectal biopsies obtained from untreated patients with quiescent ulcerative colitis.

\section{Methods}

PREPARATION OF INHIBITORY DRUGS

Prednisolone phosphate (Organon Laboratories), sulphapyridine (Sigma Chemical Co), and N-acetyl

\footnotetext{
"Address for reprints: Department of Medicine. University Hospital. Nottingham. NG7 2UH.

Received for publication + Mav 1982
}

5-ASA (Pharmacia) were dissolved directly in Tris $\mathrm{HCl}$. Dilutions of indomethacin (Merck, Sharp and Dohme) were made from a $2 \mathrm{mg} / \mathrm{ml}$ stock solution prepared in sodium carbonate. Flurbiprofen (Boots Chemical Co) and sulphasalazine (Pharmacia) were dissolved in Tris $\mathrm{HCl}$ at $\mathrm{pH} 8.5$ to make stock solutions.

For 5-ASA a modified procedure was used. Solutions of 5 -ASA $\left(5.95 \times 10^{-2} \mathrm{M}(1 \mathrm{~g} / 100 \mathrm{ml})\right)$ prepared under argon for enema administration (Ferring Pharmaceuticals) were used as the source of active drug. Placebo enemas with identical additives (sodium chloride $3.45 \times 10^{-2} \mathrm{M}(200 \mathrm{mg}$ / $100 \mathrm{ml}$ ) disodium orthophosphate $3.09 \times 10^{-2} \mathrm{M}$ $(500 \mathrm{mg} / 100 \mathrm{ml})$ potassium metabisulphite $4.50 \times 10^{-3} \mathrm{M}(100 \mathrm{mg} / 100 \mathrm{ml})$ sodium EDTA $5 \times 10^{-3}$ M $\left.(20 \mathrm{mg} / 100 \mathrm{ml})\right)$ were used for homogenising tissue and making drug dilutions. Before use, the $\mathrm{pH}$ of each solution was manipulated using Tris and $\mathrm{HCl}$ solutions to achieve a final Tris $\mathrm{HCl}$ concentration of $0 \cdot 15 \mathrm{M}$ and a $\mathrm{pH}$ of $7 \cdot 4$.

\section{INCUBATION CONDITIONS}

Single rectal biopsies (weighing 17-45 mg) were excised from patients with inactive ulcerative colitis who were receiving no treatment. They were frozen in liquid nitrogen and stored at $-70^{\circ} \mathrm{C}$ until used. The frozen biopsy was then added to $1.0 \mathrm{ml}$ of ice cold Tris $\mathrm{HCl}, \mathrm{pH} 7 \cdot 4,0 \cdot 15 \mathrm{M}$ with sodium EDTA $5 \times 10^{-3} \mathrm{M}$ in a Dual ground glass homogeniser and homogenised using a standardised action. 
Microscopy showed the suspension to consist largely of broken cells, with fibrous tissue from the submucosa unhomogenised.

The volume of the homogenate was adjusted to contain 5-20 mg (wet weight) of tissue per ml. 200 $\mu \mathrm{l}$ aliquots were mixed with serial dilutions of inhibitory drugs in Tris $\mathrm{HCl}$ and preincubated on ice for 20 minutes. $\mathrm{PGE}_{2}$ synthesis during homogenisation was measured in aliquots extracted immediately after homogenistion and without incubation.

The reaction was started by the addition of $50 \mu \mathrm{l}$ arachidonic acid (final concentration $6 \cdot 1 \times 10^{-} 5 \mathrm{M}$ $(20 \mu \mathrm{g} / \mathrm{ml}))$ in Tris $\mathrm{HCl}$ containing cofactors (adrenaline $3.0 \times 10^{-3} \mathrm{M}(1 \mathrm{mg} / \mathrm{ml})$ and reduced glutathione $1.3 \times 10^{-3} \mathrm{M}(400 \mu \mathrm{g} / \mathrm{ml})$ final concentrations). The reaction tubes were incubated at $37^{\circ} \mathrm{C}$ for 30 minutes in a rocking water bath. The reaction was stopped by the addition of 1 volume of ice cold ethanol containing indomethacin $10^{-3.3} \mathrm{M}$ $\left(0 \cdot 35 \mu \mathrm{g} / \mathrm{ml}\right.$, final concentration) and $\left(\mathrm{H}_{3}\right) \mathrm{PGE}_{2}$ (c. $500 \mathrm{cpm}, 0.23 \mathrm{mCi} /$ tube, specific activity $160 \mathrm{Ci} /$ mmol, Radiochemical Centre, Amersham) for estimation of recovery. The concentration of the drug under investigation was adjusted in each tube to the maximum concentration used during incubation. Each reaction mixture was then extracted into chloroform and resuspended for assay in phosphate buffered saline. $\mathrm{PGE}_{2}$ was measured by radioimmunoassay as described elsewhere. ${ }^{6}$

\section{CONSTRUCTION OF DOSE RESPONSE CURVES}

Three of four individual dose response curves using rectal mucosa from different patients and single incubation per drug concentration were constructed for indomethacin, flurbiprofen, $\mathrm{N}$-acetyl 5-ASA, prednisolone, and sulphapyridine. For sulphasalazine, 5-ASA, and sulphapyridine, individual dose response curves were obtained using mucosa from two to four different patients with incubations in duplicate or triplicate. With each drug the results from individual patients were used to construct overall mean values; here each point therefore represents the mean of up to nine observations.

\section{Results}

CHARACTERISTICS OF THE REACTION

The coefficient of variation for duplicate observations was $16.9 \% \quad(n=48)$. There was a modest effect on $\mathrm{pH}$ with maximum synthesis around physiological $\mathrm{pH}$. $\mathrm{PGE}_{2}$ synthesis by boiled biopsies was usually less than $10 \%$ of that by unboiled biopsies. Both adrenaline and reduced glutathione stimulated $\mathrm{PGE}_{2}$ synthesis; with both cofactors there was an additive effect with stimulation to $243 \pm 48 \%$ of that seen without cofactors $(n=4)$.

\section{EFFECT OF INHIBITORS}

The Table shows individual data for all drugs studied. No inhibition could be seen for prednisolone (101.2 $29.8 \%$ control values at $10^{-2} \mathrm{M}$ $(3.6 \mathrm{mg} / \mathrm{ml}), \mathrm{n}=3$ ) or sulphapyridine (mean $115.0 \pm 15.2 \%$ of control values at $10^{-2} \mathrm{M}(2.5$ $\mathrm{mg} / \mathrm{ml}) . \mathrm{n}=3$, tested at highest concentration only). High concentrations of 5-ASA inhibited synthesis of $\mathrm{PGE}_{2}$ (mean IC50) $\left.2.29 \times 10^{-2} \mathrm{M}(3.9 \mathrm{mg} / \mathrm{ml})\right)$. As shown in Fig. 1 its potency was similar in all four individuals investigated. The potency of $\mathrm{N}$-acetyl 5-ASA and sulphasalazine was similar to that of 5-ASA but indomethacin and flurbiprofen were about five orders of magnitude more potent. The overall mean values for all the subjects have been used to compare these drugs graphically in Fig. 2.

\section{Discussion}

These data show that sulphasalazine and 5-ASA but not sulphapyridine can inhibit the prostaglandin synthetase activity of human rectal mucosa. The

Table $P G E_{2}$ synthesis by human rectal mucosa: effect of drugs in individual patients

\begin{tabular}{|c|c|c|c|}
\hline & \multirow{2}{*}{$\begin{array}{l}\text { IC } 50 \\
\text { (molar) }\end{array}$} & \multicolumn{2}{|c|}{ Maximum inhibition } \\
\hline & & \% Inhibition* & Concentration \\
\hline \multirow[t]{4}{*}{ Indomethacin } & $7 \cdot 0 \times 10^{-x}$ & $78 \cdot()$ & $10^{-5} \mathrm{M}$ \\
\hline & $8.9 \times 10^{-x}$ & $95 \cdot 6$ & \multirow{3}{*}{$10+M$} \\
\hline & $2.0 \times 10^{-7}$ & 96.4 & \\
\hline & $8.2 \times 10^{-7}$ & $94 \cdot 6$ & \\
\hline \multirow[t]{4}{*}{ Flurbiprofen } & $2.9 \times 10^{-7}$ & $86 \cdot 3$ & \multirow{4}{*}{$10^{-3} \mathrm{M}$} \\
\hline & $3 \cdot() \times 10^{-7}$ & $96 \cdot 2$ & \\
\hline & $6 \cdot 1 \times 10^{-7}$ & $86 \cdot 5$ & \\
\hline & $6.5 \times 10^{-7}$ & 79.9 & \\
\hline \multirow[t]{2}{*}{ Sulphasalazinc } & c $3.0 \times 10^{-2}$ & $48 \cdot 4$ & \multirow{2}{*}{$3 \times 10 \div M$} \\
\hline & $>3 \cdot\left(0 \times 10^{-2}\right.$ & 4()$\cdot()$ & \\
\hline \multirow[t]{4}{*}{ 5-ASA } & $1.7 \times 10^{-2}$ & $81 \cdot 1$ & \multirow{4}{*}{$3 \times 10^{-2} \mathrm{M}$} \\
\hline & $2.4 \times 10^{-2}$ & $63 \cdot 0$ & \\
\hline & $2.6 \times 10^{-2}$ & $55 \cdot 7$ & \\
\hline & $2.6 \times 10^{-2}$ & $55 \cdot 7$ & \\
\hline \multirow[t]{3}{*}{ N-acetyl 5-ASA } & $1.4 \times 10^{-3}$ & $67 \cdot 2$ & \multirow{3}{*}{$\begin{array}{l}3 \times 10^{-3} \mathrm{M} \\
10^{-2} \mathrm{M} \\
3 \times 10^{-3} \mathrm{M}\end{array}$} \\
\hline & $3.0 \times 10^{-3}$ & $58 \cdot()$ & \\
\hline & $>3 \cdot() \times 10^{-3}$ & $31 \cdot 1$ & \\
\hline \multirow[t]{3}{*}{ Sulphapyridine } & - & $8 \cdot 4$ & \multirow{3}{*}{$3 \times 10^{-2} \mathrm{M}$} \\
\hline & - & 3.4 & \\
\hline & - & $-21 \cdot 8$ & \\
\hline \multirow[t]{3}{*}{ Prednisolone } & - & $15 \cdot 0$ & \multirow{3}{*}{$10^{-2} \mathrm{M}$} \\
\hline & - & $0 \cdot 3$ & \\
\hline & - & $-19 \cdot()$ & \\
\hline
\end{tabular}

Individual IC 50 values are shown in the first column. The maximum inhibition achieved and inhibitor concentration used are shown in the last two columns.

${ }^{*}$ Negative values indicate enhanced synthesis. 
Fig. 1 Dose responsc curres for the effect of 5 -ASA on the rectal mucosa of four differem individuals. In e'ach case' the' mean values of wo or three duplicate observations (with SEM) are shown.
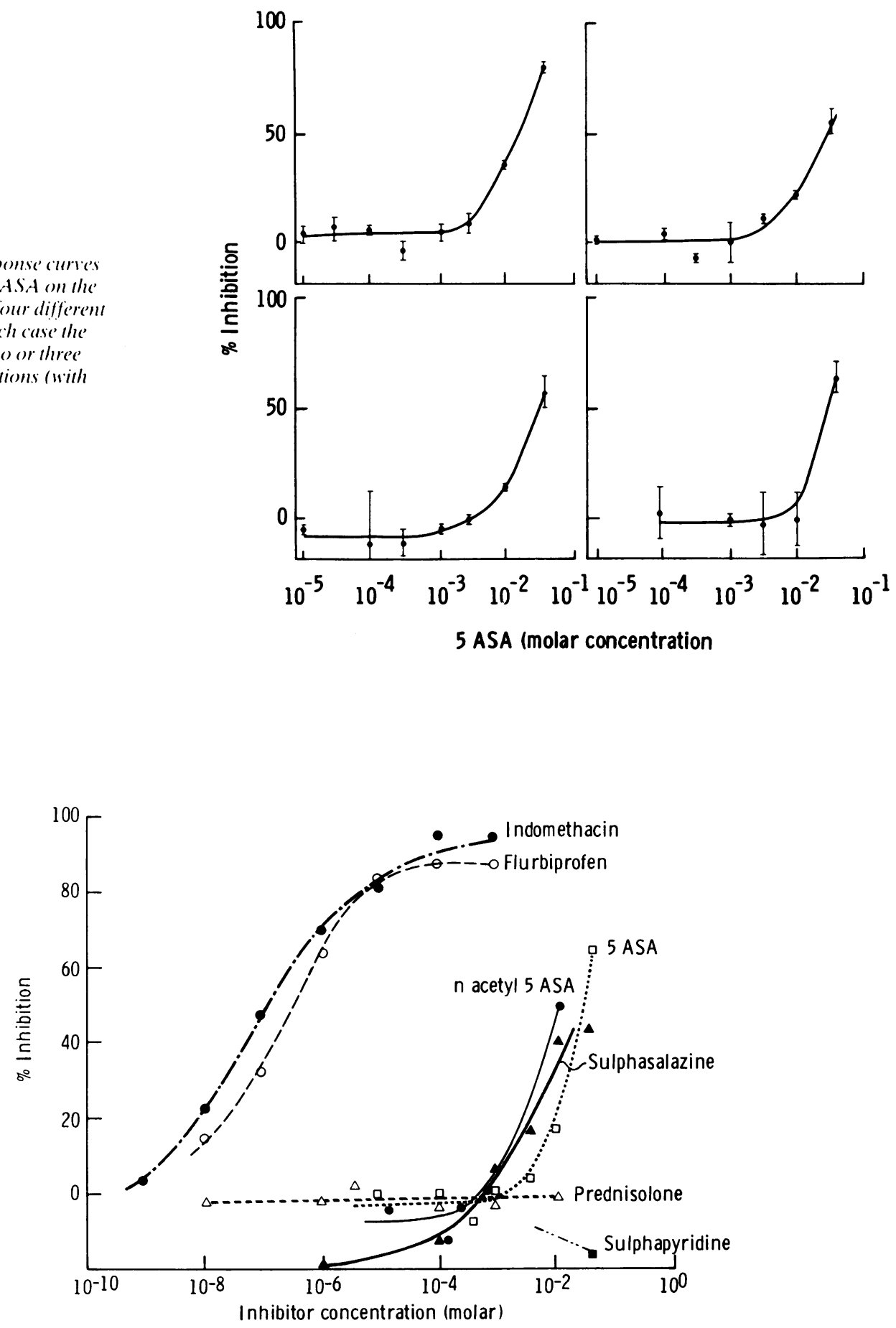

Fig. 2 Overall mean dose response curves for the drugs studied. In each case results from two, three or four individuals (shown in Table) have been averaged for each point shown. 
results parallel the clinical observation that sulphasalazine and 5 amino salicylic acid when administered by enema to patients with active disease are therapeutically potent, while sulphapyridine is not. ${ }^{7}$ Prednisolone, which has anti-inflammatory properties in ulcerative colitis, exerts no pharmacological inhibition of prostaglandin synthetase but has previously been shown to reduce basal prostaglandin synthesis in intact human rectal mucosa maintained in organ culture. ${ }^{5}$ This may be attributed to its ability in living cells to induce synthesis of a polypeptide, macrocortin, which inhibits the release of free arachidonic acid." In addition, one of us has proposed that it may also induce synthesis of a local cyclooxygenase inhibitor. " Neither of these properties would, however, apply with homogenates in vitro.

The concentrations of 5-ASA and sulphasalazine required to inhibit prostaglandin synthesis are high and the data are open to the possible criticism that this may not reflect true competitive inhibition. The concentrations of 5-ASA required for inhibition, however, are similar to those measured in the faeces of patients taking sulphasalazine. ${ }^{8} \mathrm{~N}$-acetyl 5-ASA is a derivative of 5-ASA which is therapeutically active when adminstered topically; ${ }^{\prime}$ its potency as an inhibitor of prostaglandin synthesis is similar to that of 5-ASA.

There are at present two main views as to the role of prostaglandins in ulcerative colitis. The present data support the interpretation that prostaglandin synthesis contributes to an excessive inflammatory reaction and that inhibition of this synthesis is therefore desirable. The data also show, however, that indomethacin and flurbiprofen are more potent than 5-ASA as inhibitors of prostaglandin synthesis by human rectal mucosa but they do not appear to be effective agents in the treatment of ulcerative colitis. ${ }^{10}$ "11 A detailed analysis of treatment of active ulcerative colitis by flurbiprofen showed that this drug had a number of deleterious effects. ${ }^{12}$

Such results have led to the alternative view that prostaglandins may be 'cyto-protective' in ulcerative colitis. In support of this proposal, it has been shown that sulphasalazine (but not 5-ASA) can inhibit prostaglandin metabolism in rabbit colon, ${ }^{12}$ and that 5-ASA can lead to enhanced prostacyclin $\left(\mathrm{PGI}_{2}\right)$ synthesis by human rectal mucosa. ${ }^{13}$ These data show that, in some circumstances, sulphasalazine and 5-ASA might lead to enhanced rather than reduced levels of mucosal prostaglandins. There is at present, however, very little direct evidence that this would lead to a 'cyto-protective' effect in the colon such as occurs with prostaglandins in the stomach. Furthermore, where 5-ASA was shown to enhance prostcyclin synthesis, inhibition was observed at the higher concentrations which were similar to those found in the faeces, and to those used in the experiments reported here. ${ }^{13}$

A third theory can be proposed as to the mode of action of sulphasalazine in ulcerative colitis. Weak inhibitors of prostaglandin synthetase have been shown to inhibit lipoxygenase pathways which may lead to the production of non-prostaglandin hydroxy acid products of arachidonic acid metabolism $;{ }^{14}$ this is associated with an ability to reduce the accumulation of white cells at sites of inflammation. ${ }^{15}$ By contrast, potent prostaglandin synthetase inhibitors have little effect on white cell accumulation and can divert arachidonic acid metabolism along lipoxygenase pathways ${ }^{16}$ which have been shown to exist in human colonic mucosa. ${ }^{17}$ The possibility that sulphasalazine or one of its cleavage products may inhibit lipoxygenase activity is therefore currently under investigation.

\section{References}

1 Gould SR. Assay of prostaglandin-like substances in the faeces and their measurement in ulcerative colitis. Prostaglandins 1976; 11: 489-97.

2 Sharon P. Ligumsky M. Rachmilewitz D. Zor U. Role of prostaglandins in ulcerative colitis: enhanced production during active disease and inhibition of sulfasalazine. Gastroenterology, 1978: 75: 638-4().

3 Smith PR. Dawson DJ. Swan CHJ. Prostaglandin synthetase activity in acute ulcerative colitis: effects of treatment with sulphasalazine. codeine phosphate and prednisolone. Gut 1979: 20: 8(12-5.

4 Rampton DS, Sladen GE. Youlten LJF. Rectal mucosal prostaglandin $E_{2}$ release and its relation to disease activity. electrical potential difference and treatment in ulcerative colitis. Gut 198(): 21: 591-6.

5 Hawkey CJ. Truelove SC. Effect of prednisolone on prostaglandin synthesis by rectal mucosa in ulcerative colitis: investigation by laminar flow bioassay and radioimmunoassay. Gut 1981; 22: 1901-3.

6 Hawkey CJ. Evidence that prednisolone is inhibitory to the cyclooxygenase activity of human rectal mucosa. Prostaglandins 1982; 23: 397-410.

7 Azad Kahn AK. Piris J. Truelove SC. An experiment to determine the active therapeutic moiety of sulphasalazine. Lancet 1977: 2: 892-5.

8 Peppercorn MA, Goldman P. Distribution studies of salicylazo-sulfapyridine and its metabolites. Gastroenterology 1973; 64: 240-5.

9 Willoughby CP, Piris J, Truelove SC. The effect of topical $\mathrm{N}$-acetyl 5-amino salicylic acid in ulcerative colitis. Scand J Gastroenterol 1980; 15: 715-9.

10 Gilat T, Ratan J, Rosen. P, Peled Y. Prostaglandins and ulcerative colitis. Gastroenterology 1979; 76: 1083. 
11 Rampton DS. Sladen (jE. Prostaglandin sinthesis inhibitors in ulcerative colitis: flurbiprofion compared with conventional treatment. Prostaglandins 1981: 21: 417-25.

12 Hoult JRS. Moore PK. Sulphasalazine is a potent inhibitor of PG15 hydroxydehydrogenase: possible basis for therapeutic action in ulcerative colitis. $\mathrm{Br} J$ Pharmacol 197s: 64: 6-8.

1.3 Hoult JRS. Page H. 5 amino salicylic acid. a co-factor for colonic prostacyclin synthesis:? Lancet 1981: $21: 255$

If Walker JR. Dawson W. Inhibition of rabbit PMN lipoxygenase activity by henoxaprofen. $J$ Pharm Pharmacol 1979: 31: 778-80.
15 Higgs (;A. Flower RJ. Vanc JR. A new approach to anti-intlammatory drugs. Bioche'm Pharmacol 1979): 28 : |9.59-61.

16 Siegel MI. Meconnell RT. Cuatrecasas P. Aspirin-like drugs interfere with arachidonate metabolism by inhibition of the 12-hydroperoxy-5. 8. 10. 1tcicosatetracnoic acid peroxidase activity of the lipoxygenase pathway. Proc Natl Acad Sci USA 1979; 76: $377+3778$.

17 Hawkey (J. Boughton Smith NK. Whittle BJR. Synthesis of lipoxygenase and cyclooxygenase products by human colonic mucosa. (Abstract.) (jut 1982: 23: A.897. 